\title{
Direct Measurement of Enantiomeric Ratios of Enzymatic Resolution by Chiral High-Performance Liquid Chromatography
}

\author{
SHIH-HSIUNG WU, SU-YUAN LAI, SHU-LING LIN, FEI-YA CHU, AND KUNG-TSUNG WANG \\ Institute of Biological Chemistry, Academia Sinica, and Institute of Biochemical Sciences, National \\ Taiwan University, Taiwan, Republic of China
}

\begin{abstract}
R)- and (S)-Methyl 2-(phenoxy)propionate and their acids could be separated simultaneously by a Chiralcel OD or OK column, while (R)- and (S)-methyl 2-(4-chlorophenoxy)propionate and their acids were separated concurrently only by an OK column. This is a novel and facile way to measure the enantiomeric excesses of the remaining substrate and product in the reaction of enzymatic resolution; enantiomeric ratios could then be calculated.
\end{abstract}

KEY WORDS: enzymatic resolution, chiral HPLC, enantiomeric ratio, enantiomeric excess, 2-(phenoxy)propionate, 2-(4-chlorophenoxy)propionate

\section{INTRODUCTION}

Enzymes are chiral catalysts in living systems. They have been used in the preparation of chiral compounds for a long time. ${ }^{1}$ In particular, hydrolytic enzymes such as lipases and proteases are suitable for asymmetrically synthetic applications because they accept a broad range of compounds as substrates and many of them are highly enantioselective. ${ }^{2}$ In the enzymatic kinetic resolution of enantiomers, the enantiomeric excesses (ee) of remaining substrates $\left(e_{\mathrm{s}}\right)$ and products $\left(e e_{p}\right)$ are variable and dependent on the extent of conversion $(C)$, so they are not suitable as indexes for comparing the enantioselectivity of different enzymes toward the same substrate in the same reaction conditions. ${ }^{3}$ In 1982, Sih and his co-workers developed Equations (1) and (2) to calculate the $E$ value, which is a biochemical constant and gradually has been recognized as an index to express enantiospecificity. ${ }^{4}$

$$
\begin{gathered}
\frac{\operatorname{In}\left[(1-C)\left(1-e e_{s}\right)\right]}{\operatorname{In}\left[(1-C)\left(1+e e_{s}\right)\right]}=E \quad \text { or } \quad \frac{\operatorname{In}\left[1-C\left(1+e e_{p}\right)\right]}{\operatorname{In}\left[1-C\left(1-e e_{p}\right)\right]}=E \\
C=\frac{e^{e e_{s}}}{e e_{s}+e e_{p}}
\end{gathered}
$$

To calculate $E$ values, conversion $(C)$ and ee $\left(e^{\mathrm{s}}\right.$ and $e_{p}$ ) should be measured first. Generally, the procedures to measure $e_{s}$ and $e_{p}$ are tedious. In this article, a facile way to separate (R)- and (S)-methyl 2(phenoxy)propionate and their counterpart acids simultaneously by chiral HPLC is developed and this method can be used to measure the $e_{\mathrm{s}}$ and $\mathrm{ee}_{\mathrm{p}}$ of 2 (phenoxy)propionate $(1,3)$ and its related compounds such as 2-(4-chlorophenoxy)propionate $(2,4)$ in the resolution of enzymatic reactions.

$$
\begin{aligned}
& \underline{1}: \mathrm{R}_{1}=\mathrm{H} ; \mathrm{R}_{2}=\mathrm{CH}_{3} \\
& \underline{2}: \mathrm{R}_{1}=\mathrm{Cl} ; \mathrm{R}_{2}=\mathrm{CH}_{3} \\
& \underline{3}: \mathrm{R}_{1}=\mathrm{H} ; \mathrm{R}_{2}=\mathrm{H} \\
& \underline{4}: \mathrm{R}_{1}=\mathrm{Cl} ; \mathrm{R}_{2}=\mathrm{H}
\end{aligned}
$$

Structure 1.

\section{MATERIALS AND METHODS}

Lipase AP6 (Aspergillus niger), lipase N (Rhizopus niveus), lipase MAP (Mucor meihei), lipase CE-5 ( $\mathrm{Hu}$ micola lanuginosa), lipase AK (Pseudomonas sp.), and lipase AY (Candida cylindracea) were obtained from Amano, Japan. Alcalase was purchased from NOVO, Denmark and lipase OF and lipase MY (Candida cylindracea) were from Meito Sangyo Co., Ltd., Japan. TLC was performed on silica gel G.60 (E. Merck, FRG) precoated on a glass plate. All solvents were obtained from Alps Chemical Co., Taiwan. The Chiralcel OD and $\mathrm{OK}$ columns $(25 \mathrm{~cm} \times 4.6 \mathrm{~mm}$ i.d. $)$ were products of Daicel Chemical Industries, Ltd., Japan. An HPLC System of Waters Assoc. (Milford, MA) was used for the

Received for publication May 30, 1990; accepted July 23, 1990. Address reprint requests to Shih-Hsiung Wu at Institute of Biochemical Sciences, National Taiwan University, Taiwan, Republic of China. 


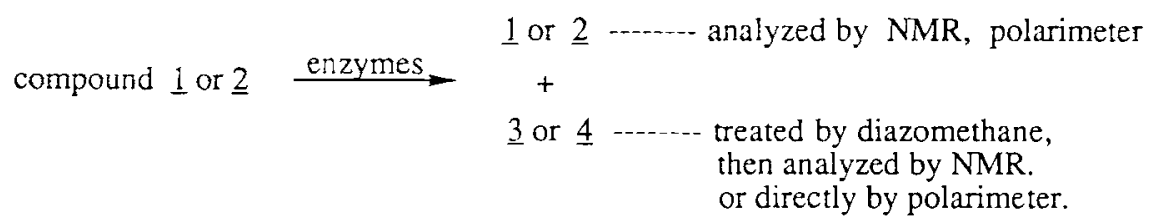

Scheme 1.

analytical separations, which consisted of one M6000A solvent delivery unit and a U6K Universal liquid chromatograph injector, coupled to a M450 variablewavelength UV spectrophotometer and an SIC chromatocorder 12 integrator, System Instruments Co., Ltd., Japan. 2-(4-Chlorophenoxy)propionic acid and 2(phenoxy)propionic acid were purchased from Aldrich Chemical Co., Inc. and their methyl esters were prepared by diazomethane treatment.

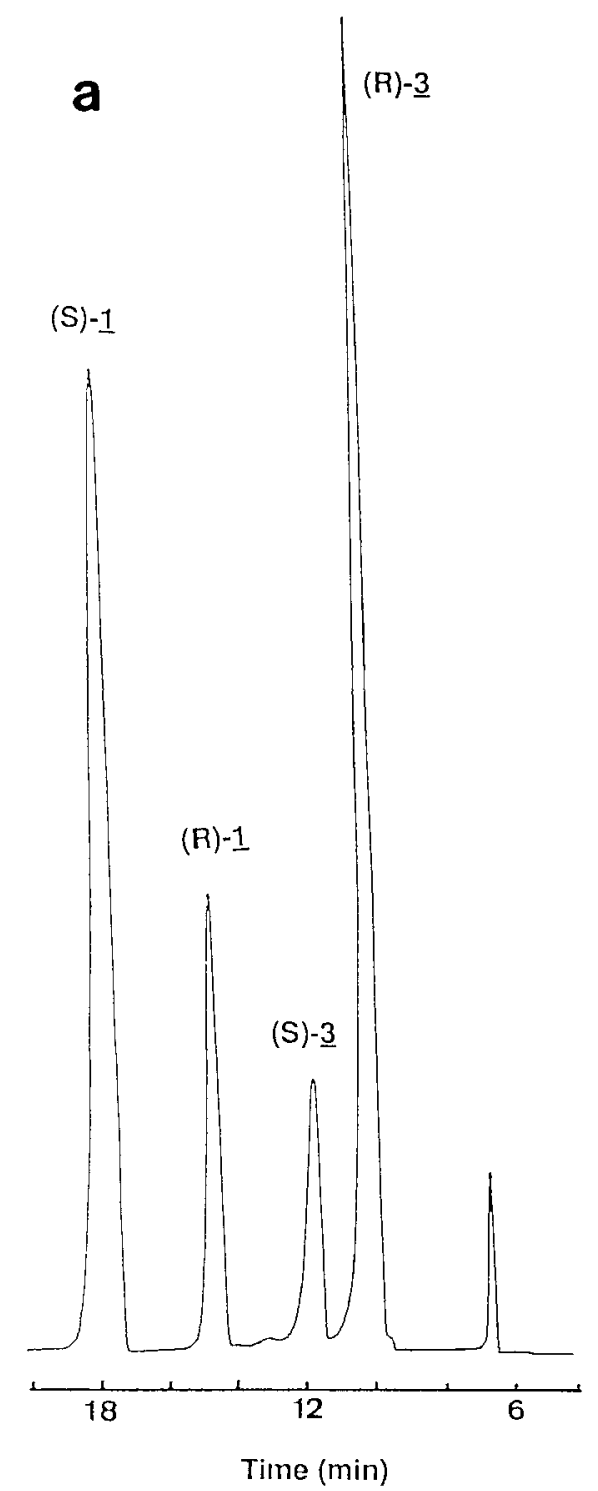

\section{General Procedure for the Resolution of Compounds 1 and 2 by Enzymatic Hydrolysis}

To $100 \mathrm{mg}(0.47 \mathrm{mmol})$ of racemic methyl ester, suspended in $2 \mathrm{ml}$ of $0.2 \mathrm{M}$ phosphate buffer, $\mathrm{pH} 7.1$, was added $30 \mathrm{mg}$ of the crude enzyme. The reaction mixture was stirred at room temperature, and the progress of the reaction was roughly monitored by silica gel TLC with $n$-hexane/EtOAc (4:1, by volume) as the develop-

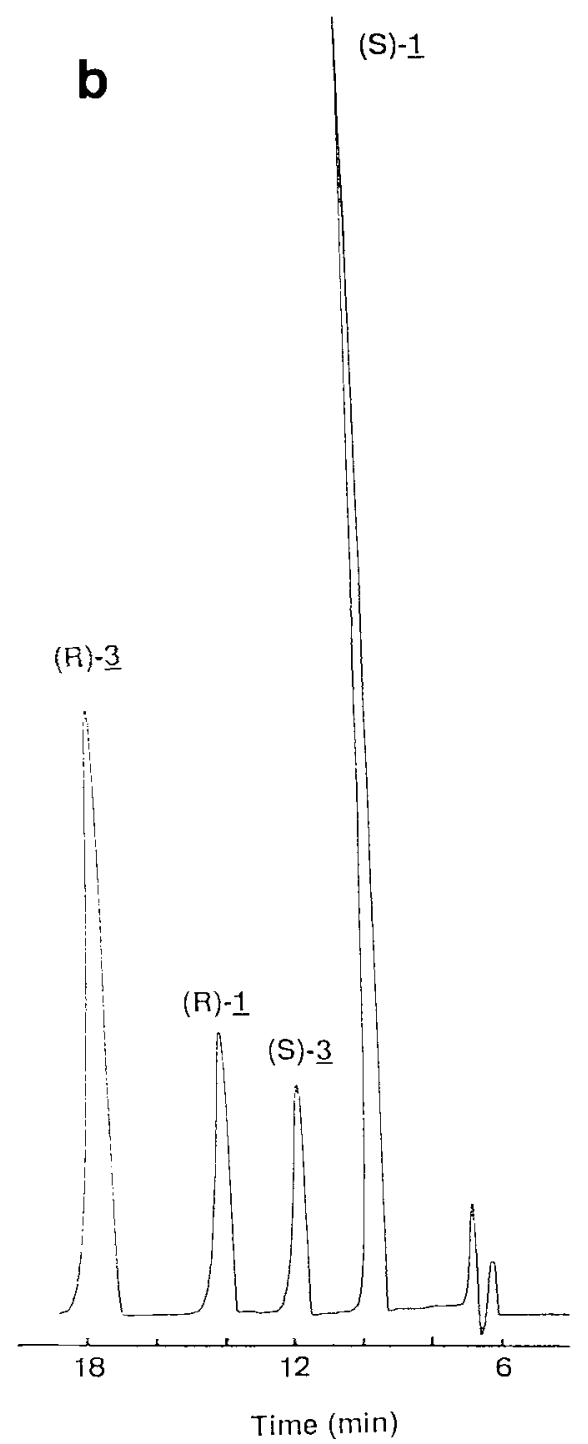

Fig. 1. Separation of (R,S)-1 and (R,S)-3 by (a) Chiralcel OK column. (b) Chiralcel OD column. The conditions are described in Materials and Methods. 
ing system and visualized under UV lamp. The reaction was terminated by adjusting the $\mathrm{pH}$ of the solution to $\mathrm{pH} 2$ with $1 \mathrm{~N} \mathrm{HCl}$. The remaining ester substrate and acid product were extracted together with ether (3 $\times 2 \mathrm{ml}$ ). The ether layer was collected, treated by $\mathrm{Na}_{2} \mathrm{SO}_{4}$, and analyzed directly by chiral HPLC.

\section{Analysis of Chiral HPLC}

The extracted ether solutions were analyzed on a Chiralcel OD column at ambient temperature isocratically with $n$-hexane/isopropanol/formic acid (90:10:1, by volume) at a flow rate of $0.5 \mathrm{ml} / \mathrm{min}$ and detected at UV $254 \mathrm{~nm}$. Analysis on the Chiralcel OK column was performed under the same conditions as the OD column, except the elution was with $n$-hexane/isopropanol ( $5: 1$, by volume).

\section{Calculation of E Value}

The $e e_{s}$ and $e e_{p}$ in the resolution of enzymatic hydrolysis were determined by chiral HPLC. Based on the ee data and Equations (1) and (2), the $E$ of different enzymes could be calculated.

\section{RESULTS AND DISCUSSION}

2-(Phenoxy)-propionate and 2-(4-chlorophenoxy)propionate are potent herbicides. However, only the $R$ isomers are biologically active. In previous reports, the resolution of compounds 1 and 3 was carried out by enzymatic hydrolysis, and $\mathrm{ee}_{\mathrm{s}}$ and $\mathrm{ee}_{\mathrm{p}}$ were measured by a tedious procedure. As shown in Scheme 1, the remaining substrate and product should be separated first, then their optical purities (ee) were measured in two ways: directly by polarimeter ${ }^{5}$ or directly by NMR with chiral shift reagents. ${ }^{6,7}$ However, the determination of ee by polarimetry may suffer from serious drawbacks, such as the following: (1) The chiral product must be isolated in nearly $100 \%$ purity. (2) A relatively large quantity of the chiral compounds is required for polarimetric measurement. (3) The chiral compound must have medium to high optical rotatory power. (4) The accuracy of optical rotation is greatly influenced

TABLE 1. Separation factors $(\alpha)$, capacity factors $\left(k^{\prime}\right)$, and resolution factors $\left(\boldsymbol{R}_{\mathrm{s}}\right)$ of compounds $1,2,3$, and 4 on Chiralcel OD and OK columns

\begin{tabular}{cccccccc}
\hline & \multicolumn{3}{c}{ Chiralcel OK } & & \multicolumn{3}{c}{ Chiralcel OD } \\
\cline { 2 - 4 } \cline { 6 - 8 } Compounds & $k^{\prime}$ & $\alpha$ & $R_{\mathrm{s}}$ & & $k^{\prime}$ & $\alpha$ & $R_{\mathrm{s}}$ \\
\hline $1 \mathrm{R}$ & $\mathbf{1 . 6 6}$ & 1.38 & 2.07 & & 1.34 & 2.63 & 4.4 \\
$\mathrm{~S}$ & 2.29 & & & 0.51 & & \\
$2 \mathrm{R}$ & 1.55 & 1.66 & 3.79 & 0.34 & 1.00 & \\
$\mathrm{~S}$ & 2.57 & & & 0.34 & & \\
$3 \mathrm{R}$ & 0.65 & 1.35 & 1.07 & 1.73 & 2.14 & 3.93 \\
$\mathrm{~S}$ & 0.88 & & & 0.81 & & \\
$4 \mathrm{R}$ & 0.65 & 1.73 & 2.29 & 0.63 & 1.00 & \\
$\mathrm{~S}$ & 1.12 & & & 0.63 & & \\
\hline
\end{tabular}

TABLE 2. Enantioselective hydrolysis of methyl 2-(phenoxy)-propionate by various enzymes

\begin{tabular}{lccrccc}
\hline \multicolumn{1}{c}{ Enzymes } & $\begin{array}{c}\text { Reaction } \\
\text { time } \\
(\mathrm{h})\end{array}$ & $\begin{array}{c}\text { Pro R } \\
\text { or S }\end{array}$ & $\begin{array}{c}\mathrm{ee}_{\mathrm{s}} \\
(\%)\end{array}$ & $\begin{array}{c}\mathrm{ee}_{\mathrm{p}} \\
(\%)\end{array}$ & $\begin{array}{c}C \\
(\%)\end{array}$ & $E$ \\
\hline Alcalase & 180 & $\mathrm{~S}$ & 9 & 18 & 33 & 2 \\
Lipase AP-6 & 180 & $\mathrm{R}$ & 19 & 40 & 32 & 3 \\
Lipase AY-30 & 43 & $\mathrm{R}$ & 51 & 69 & 43 & 9 \\
Lipase AK & 200 & $\mathrm{R}$ & 8 & 47 & 15 & 3 \\
Lipase CE-5 & 180 & $\mathrm{R}$ & 24 & 90 & 21 & 21 \\
Lipase OF & 22 & $\mathrm{R}$ & 45 & 45 & 50 & 4 \\
Lipase N & 180 & $\mathrm{~S}$ & 2 & 8 & 20 & 1 \\
Lipase MY & 25 & $\mathrm{R}$ & 54 & 72 & 43 & 10.5 \\
Lipase MAP 10 & 180 & $\mathrm{R}$ & 8 & 8 & 50 & 1 \\
\hline
\end{tabular}

by temperature, solvent, concentration, and the purity of the measured compound. These shortcomings make the ee obtained from the measurement of polarimeter very unreliable. As for the determination of ee by NMR with the addition of chiral shift reagents, compounds 1 and 2 could be measured directly, while 3 and 4 should first be converted to 1 and 2 by treatment of diazomethane and then measured. The doublet of the $\alpha-\mathrm{CH}_{3}$ of 1 and 2 at $\delta 1.2 \mathrm{ppm}$ in ${ }^{1} \mathrm{H}-\mathrm{NMR}$ spectra was shifted more downfield after adding chiral shift reagents and split into two doublets, in which the signals of $R$ isomers were more downfield than those of S-isomers. ${ }^{6,7}$ Based on the ratios of two doublets, ee $e_{s}$ and $e_{p}$ were determined. In these whole procedures, there are several disadvantages: (1) The purity of the measured compounds should be very high, because a little impurity probably makes shift reagents inactive. (2) The expensive NMR machine has to be available for testing different kinds of shift reagents. (3) The procedures are tedious. In recent years, chiral columns of HPLC and GC have been introduced to measure the optical purity of chiral compounds directly and these simple methods are superior to other methods. ${ }^{8,9}$

In order to find good enzymes for kinetic resolution, nine hydrolytic enzymes are employed to hydrolyze compounds 1 and 2. From the results of Figure 1 and Tables 2 and 3, (R,S)-1 and (R,S)-3 could be separated

TABLE 3. Enantioselective hydrolysis of methyl 2-(4-chlorophenoxy)-propionate by various enzymes

\begin{tabular}{lccrrrr}
\hline Enzymes & $\begin{array}{c}\text { Reaction } \\
\text { time } \\
(\mathrm{h})\end{array}$ & $\begin{array}{c}\text { Pro R } \\
\text { or S }\end{array}$ & $\begin{array}{c}\mathrm{ee}_{\mathrm{s}} \\
(\%)\end{array}$ & $\begin{array}{c}\mathrm{ee} \\
(\%)\end{array}$ & $\begin{array}{c}\mathrm{C} \\
(\%)\end{array}$ & $E$ \\
\hline Alcalase & 180 & $\mathrm{~S}$ & 7 & 63 & 10 & 5 \\
Lipase AP-6 & 48 & $\overline{\mathrm{n}}$ & $\sim 0$ & $\sim 0$ & 25 & 1 \\
Lipase AY-30 & 48 & $\mathrm{R}$ & 33 & 62 & 35 & 6 \\
Lipase AK & 200 & $\mathrm{R}$ & 10 & 36 & 22 & 2 \\
Lipase CE-5 & 144 & $\mathrm{R}$ & 17 & 73 & 19 & 8 \\
Lipase OF & 48 & $\mathrm{R}$ & 34 & 45 & 44 & 3.5 \\
Lipase N & 180 & $\mathrm{~S}$ & 2 & 8 & 20 & 1 \\
Lipase MY & 25 & $\mathrm{R}$ & 54 & 72 & 43 & 10.5 \\
MAP 10 & 180 & $\mathrm{R}$ & 8 & 8 & 50 & 1 \\
\hline
\end{tabular}




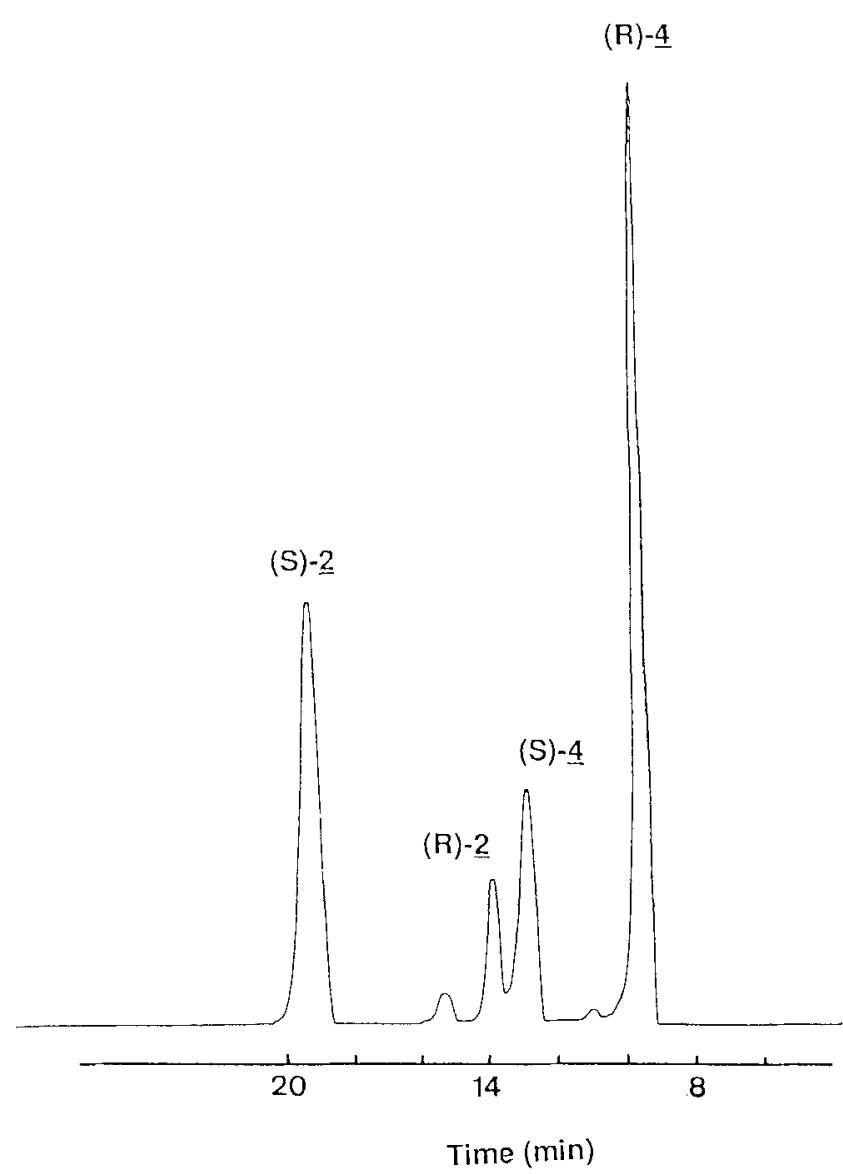

Fig. 2. Separation of (R,S)-2 and (R,S)-4 by Chiralcel OK column. The conditions are described in Materials and Methods.

simultaneously by Chiralcel OD or OK columns. (R,S)2 and (R,S)- 4 could be separated simultaneously by a Chiralcel OK column, but not by a Chiralcel OD column (Fig. 2). The enantiomeric ratios $(E)$ of enzymes for compounds 1 and 2 are calculated and listed in Table 2 and 3 .

Compared with the old methods such as NMR and polarimetry (summarized in Table 4), the chiral HPLC method has several advantages: (1) Because it is not necessary to separate the remaining substrate and product, the whole procedure is facile, easy to handle, and fast. (2) $C$, ee $e_{s}$, and $e_{p}$ can be determined concurrently. (3) the data measured by this method are more reliable. (4) ee is not greatly influenced by a little impurity in the measured compounds.
TABLE 4. Comparison of different methods on the measurement of $\mathrm{ee}_{\mathrm{p}}$ and $\mathrm{ee}_{\mathrm{s}}$

\begin{tabular}{lccc}
\hline & Polarimetry & NMR & $\begin{array}{c}\text { Chiral } \\
\text { HPLC }\end{array}$ \\
\hline $\begin{array}{l}\text { 1. Is it necessary to } \\
\text { separate the remaining } \\
\text { substrates and products? }\end{array}$ & Yes & Yes & No \\
$\begin{array}{l}\text { 2. Is a large quantity of } \\
\text { the measured } \\
\text { compounds required? }\end{array}$ & Yes & Yes & No \\
$\begin{array}{l}\text { 3. Is ee greatly influenced } \\
\text { by a little impurity in } \\
\text { the measured }\end{array}$ & Yes & Yes & No \\
$\begin{array}{l}\text { compounds? } \\
\text { 4. Are the procedures to } \\
\text { measure ee } \text { and ee }\end{array}$ & Yes & Yes & No \\
tedious? & & & \\
$\begin{array}{l}\text { 5. Are the data obtained } \\
\text { more accurate and } \\
\text { reliable? }\end{array}$ & No & Yes & Yes \\
\hline
\end{tabular}

\section{LITERATURE CITED}

1. Jones, J.B., Beck, J.F. Asymmetric synthesis and resolutions using enzymes. In: Applications of Biochemical Systems in Organic Chemistry Part I. Jones, J.B., Sih, C.J., Perlman, D., eds. Techniques of Chemistry Vol. X. New York: Wiley, 1976:107-401.

2. Sih, C.J., Wu, S.H. Resolution of enantiomers via biocatalysis. In: Topics in Stereochemistry, Vol. 19. Eliel, E.L., Wilen, S.H., eds. New York: Wiley, 1989:63-125.

3. Sih, C.J., Shieh, W.R., Chen, C.S., Wu, S.H., Girdaukas, G. Biochemical asymmetric catalysis. In: International Symposium on Bioorganic Chemistry. Breslow, R., ed. Ann. N.Y. Acad. Sci. 471:239-254, 1986.

4. Chen, C.S., Fujimoto, Y., Girdaukas, G., Sih, C.J. Quantitative analyses of biochemical kinetic resolutions of enantiomers. J. Am. Chem. Soc. 104:7294-7299, 1982.

5. Cambou, B., Klibanov, A.M. Comparison of different strategies for the lipase-catalyzed preparative resolution of racemic acids alcohols: Asymmetric hydrolysis, esterification, and transesterification. Biotechnol. Bioeng. 26:1449-1454, 1984.

6. Wu, S.H., Guo, Z.W., Sih, C.J. Enchancing the enantioselectivity of Candida lipase catalyzed ester hydrolysis via noncovalent enzyme modification. J. Am. Chem. Soc. 112:1990-1995, 1990.

7. Guo, Z.W., Sih, C.J. Enantioselective inhibition: A strategy for improving the enantioselectivity of biocatalytic systems. J. Am. Chem. Soc. 111:6836-6841, 1989.

8. Morrison, J.D., ed. Asymmetric Synthesis, Vol. 1. London: Academic Press, 1983.

9. Allenmark, S.G. Chromatographic Enantioseparation: Methods and Applications. Ellis Horwood Limited, 1988. 